\title{
Interaction of Monocytes with Cocultures of Human Aortic Wall Cells Involves Interleukins 1 and 6 with Marked Increases in Connexin43 Message
}

\author{
Mahamad Navab," Feng Liao," Gregory P. Hough," Lori A. Ross," Brian J. Van Lenten," Tripathi B. Rajavashisth," \\ Aldons J. Lusis," Hillel Laks," Davis C. Drinkwater," and Alan M. Fogelman* \\ Division of Cardiology, Department of Medicine, ${ }^{*}$ and Division of Cardiothoracic Surgery, Department of Surgery, ${ }^{8}$ School of Medicine, \\ University of California, Los Angeles, California 90024-1679; and Division of Medical Genetics, ${ }^{*}$ \\ Harbor-UCLA Medical Center, Torrance, California 90502-2064
}

\begin{abstract}
Medium from cocultures of human aortic endothelial cells (HAEC) and smooth muscle cells (HASMC) taken from the same donor contained approximately two- to fourfold more macrophage colony-stimulating factor, granulocyte/macrophage colony-stimulating factor, and up to 5.1-fold more transforming growth factor $\beta$ than could be accounted for by the sum of the activities of media from equivalent numbers of HAEC and HASMC cultured separately. After pulse labeling, immunoprecipitated $\left[{ }^{35} \mathrm{~S}\right]$ fibronectin and $\left[{ }^{14} \mathrm{C}\right]$ collagen were also found to be substantially increased in the coculture compared to the sum of HAEC and HASMC cultured separately. The cocultivation of HAEC and HASMC resulted in a 2.7 -fold increase in connexin43 messenger RNA. When direct physical contact between HAEC and HASMC was prevented by a membrane that was permeable to medium, the levels of $\left.{ }^{35} \mathrm{~S}\right]$ fibronectin and $\left[{ }^{14} \mathrm{C}\right]$ collagen in the coculture were significantly reduced. Monocytes cultured alone contained low levels of ${ }^{35}$ Sjfibronectin and $\left[{ }^{14} \mathrm{C}\right]$ collagen but when added to the coculture there was up to a 22-fold increase in $\left[^{35}\right.$ S fibronectin and a 1.9-fold increase in $\left[{ }^{14} \mathrm{C}\right]$ collagen compared to the coculture alone. The increase in fibronectin was prevented in the presence of neutralizing antibody to interleukin 1 and antibody to interleukin 6 by $45 \%$ and $67 \%$, respectively. Addition of monocytes to cocultures also induced the levels of mRNA for connexin 43 by 2.8 -fold. We conclude that the interaction of HAEC, HASMC, and monocytes in coculture can result in marked increases in the levels of several biologically important molecules and that increased gap junction formation between the cells and interleukins 1 and 6 may be partially responsible for these changes. (J. Clin. Invest. 1991.87:1763-1772.) Key words: collagen - colony-stimulating factor • endothelial cell • fibronectin • smooth muscle
\end{abstract}

\section{Introduction}

Under normal conditions there are only a limited number of smooth muscle cells (SMC) ${ }^{1}$ and monocytes present in the sub-

Address reprint requests to Dr. Navab, Division of Adult Cardiology, Room 47-123, Center for the Health Sciences, UCLA School of Medicine, Los Angeles, CA 90024-1679.

Received for publication 9 March 1990 and in revised form 7 January 1991.

1. Abbreviations used in this paper: COL/SMC, human aortic smooth muscle cell layers grown on a filter and covered with a collagen layer;

J. Clin. Invest.

(C) The American Society for Clinical Investigation, Inc. 0021-9738/91/05/1763/10 \$2.00

Volume 87, May 1991, 1763-1772 endothelial space (1). However, in the course of development of an atherosclerotic lesion there is a marked migration of monocytes and SMC into the subendothelial space (2). The presence of endothelial cells (EC), SMC, and monocytes in such a confined space might be predicted to favor cellular interactions. In tissue culture, the interaction of EC and SMC has been shown to lead to increased low density lipoprotein (LDL) receptor activity (3), increased lysosomal cholesteryl esterase activity (4), and reduced rates of SMC proliferation (5). The coculture of SMC and EC has also been shown to alter the amount and the composition of the extracellular matrix (6). Recently two laboratories $(7,8)$ have shown that bovine EC and pericytes or SMC, when cultured together, produced active transforming growth factor- $\beta$ (TGF- $\beta$ ) in the culture medium. Both EC (9) and SMC (10) have been shown to express message for connexin 43 , a member of the family of related gap junction proteins. These junctions are membrane structures involved in intercellular communication and have been implicated in buffering of cytoplasmic ions (11), synchronization of cellular behavior such as contraction of myocardial cells (12), growth control and embryonic differentiation (13), and suppression of deleterious effects of somatic cell mutations in a variety of enzymes (14). The induction of connexin 43 as a result of the interaction of EC, SMC, and monocytes in coculture has not been previously reported. In the present report we demonstrate that the coculture of adult human aortic EC (HAEC) with adult human aortic SMC (HASMC) taken from the same donor resulted in increased levels of several biologically important molecules when the cells were cultured under conditions permitting direct cell-cell contact. Moreover, we show that the addition of human monocytes to the coculture markedly enhanced the levels of these matrix components. We also present evidence indicating that cell-cell interaction results in increased induction of mRNA for connexin 43 and that interleukins 1 and 6 (IL-1 and IL-6) are involved in increased levels of matrix proteins.

\section{Methods}

Materials. Tissue culture medium, reagents, fetal bovine serum (FBS), and pooled human serum (HS) were obtained from sources described (15). Microporous filters, Transwells, and plasticware were purchased

$\mathrm{EC} / \mathrm{COL}$, endothelial cells grown on a layer of collagen on a filter; $\mathrm{EC} / \mathrm{COL} / \mathrm{SMC}$, a multilayer of smooth muscle cells grown on a filter, covered with a layer of collagen, with an endothelial monolayer grown on the surface of collagen; FBS, fetal bovine serum; FN, fibronectin; GM-CSF, granulocyte/macrophage colony-stimulating factor; HA, human aortic; HI, heat-inactivated; HS, pooled human serum; IDME, Iscoves modified Eagle's medium; M-CSF, macrophage colony-stimulating factor; RI, radiolabeled and immunoprecipitated; SMC, human aortic smooth muscle cells; TGF- $\beta$, transforming growth factor- $\beta$. 
from Costar Corp., Cambridge, MA, and from sources reported (16). Purified, recombinant human macrophage colony-stimulating factor (M-CSF) and granulocyte/macrophage CSF (GM-CSF) were kindly provided by Dr. Steve Clark, Genetics Institute, Cambridge, MA. Neutralizing antibody to M-CSF was a gift of Dr. E. R. Stanley, Albert Einstein College of Medicine, Bronx, NY; and neutralizing antibody to GM-CSF was kindly provided by Dr. Judith Gasson, University of California, Los Angeles. TGF- $\beta_{1}(100-B)$ and neutralizing antibody to TGF- $\beta$ (AB-10-NA), to IL-1 (AB-202-NA), and to IL-6 (AB-210-NA) were purchased from R\&D Systems, Minneapolis, MN. The AKR-2B cell line was a gift of Dr. Harold Moses, Vanderbilt University, Nashville, TN. ${ }^{35}$ S $]$ methionine (specific activity $1,254 \mathrm{Ci} / \mathrm{mmol}$, SJ.1015) was from Amersham Corp., Arlington Heights, IL; and $\left[\mathrm{U}-{ }^{14} \mathrm{C}\right]$-proline (specific activity $250 \mathrm{mCi} / \mathrm{mmol}, 10117 \mathrm{E}$ ) was from ICN Radiochemicals, Irvine, CA. Human fibronectin (no. 4008) was obtained from Collaborative Research, Lexington, MA. Anti-human fibronectin antibody (IgG fraction, no. 0201-0832), was obtained from Cappel Laboratories, Organon Technika Corp., Malvern, PA; and antibody to human type I collagen (no. AB745) was purchased from Chemicon International, Temecula, CA. Tricine mini-gels (EC 1675) were from Novex, Encinitas, CA. Protein-A Sepharose and collagen type I (C 3511) were obtained from Sigma Chemical Co., St. Louis, MO. The cDNA probes for connexins32 and $43(17,18)$ were a gift from Drs. Denise Polacek and Peter Davies of University of Chicago and Dr. David L. Paul of Harvard University.

Cells and cultures. HAEC, SMC, and human peripheral blood monocytes were isolated as described $(19,20)$. In brief, polycarbonate filters with $1-\mu \mathrm{m}$ pore diameter were coated with gelatin and assembled in the U-shaped chambers of a transport device forming separate compartments on each side of the filter (15). HASMC were grown on filters at $1.5 \times 10^{5}$ cells $/ \mathrm{cm}^{2}$ and allowed to grow for $2 \mathrm{~d}$ and cover the surface of the filter. The SMC were then covered with a solution (5 $\left.\mu \mathrm{l} / \mathrm{cm}^{2}\right)$ of native collagen type I $(0.2 \% \mathrm{wt} / \mathrm{vol})$ which was allowed to polymerize and form a thin gel layer at $37^{\circ} \mathrm{C}(19)$. The collagen layer was subsequently washed with culture medium at $37^{\circ} \mathrm{C}$ and HAEC were seeded at $2.5 \times 10^{6} \mathrm{cells} / \mathrm{cm}^{2}$ and allowed to grow and form a complete monolayer of confluent EC in 24-48 $h$ (19). For mixed cocultures, the procedure described by Antonelli-Orlidge and colleagues (7) was followed where EC were added to subconfluent SMC and the resulting coculture was in the form of a layer of mixed islands (or patches) of EC and SMC. In all experiments, the propagated HAEC, and their autologous (matching) HASMC (from the same donor) at passage levels of 5-7 were used. In some experiments cocultures were formed on filters in the form of Transwells. Blood monocytes were obtained from individuals from a large pool of healthy donors by a modification of the Recalde procedure (20). The human monocytes isolated by the modified Recalde procedure have been demonstrated to be comparable to monocytes isolated by conventional procedures in terms of cell viability, protein content, purity, and monocyte chemotaxis $(19,20)$. A portion of isolated monocytes was cryopreserved in growth medium containing 10\% dimethyl sulfoxide according to standard procedures (21) and were found to be indistinguishable from freshly isolated monocytes in adhesion, chemotaxis, and their interaction with HAEC and HASMC. The use of cryopreserved monocytes was found to be a useful approach for reducing the problem of large variability in different monocyte isolates from various donors. Cocultures, or their components, in tissue culture flasks or on microporous filters were cultured as described (19), except that in the present study the growth medium (20\% heat-inactivated FBS in medium 199) was replaced with $10-15 \%$ heat-inactivated pooled human serum (HIHS) in Iscove's modified Eagle's medium (IDME). This resulted in improved purity, growth pattern, and cell morphology. The HAEC and HASMC isolated from the aortic specimens were shown to be essentially free of contaminating cells. Thus, the HAEC were pure as determined by morphology and by assays for factor VIII-related antigen, uptake of LDL modified by malondialdehyde, and labeled with 1,1'-dioctadecyl-3,3,3',3'-tetramethylindo-carbocyanine perchlorate, and for angiotensin-converting enzyme activity (19). The HASMC were determined to be pure as judged by morphology and by immunohistochemical staining using the monoclonal antibody HHF-35 (19). In all experiments the number of HAEC and HASMC were equivalent whether the cells were cultured separately or together. In all cases the HAEC and HASMC within each experiment were from the same donor and aortic specimen. For collection of conditioned medium for TGF- $\beta$ bioassays, after three 3- $h$ incubations in IDME, the cultures were incubated in IDME without serum present and 24-h conditioned media were collected. Protease inhibitors pepstatin $(1 \mu \mathrm{g} / \mathrm{ml})$, leupeptin $(1 \mu \mathrm{g} / \mathrm{ml})$, and aprotinin $(3 \mu \mathrm{g} / \mathrm{ml})$, plus human serum albumin $(0.05 \% \mathrm{wt} / \mathrm{vol})$ were added, the media were centrifuged at $1,500 \mathrm{~g}$ for $10 \mathrm{~min}$, and the supernatant solutions were concentrated 10-fold with Centricon units (molecular weight cutoff of 10,000 , Amicon Corp., Danvers, MA). A portion of the medium was transiently acidified $(22)$ before storage at $-20^{\circ} \mathrm{C}$. Experiments on the activation of TGF- $\beta$ by mixed cocultures of HAEC and HASMC were carried out in a manner identical to that reported by Antonelli-Orlidge and colleagues (7). For CSF bioassays the medium incubated with the artery wall cells contained $2.5 \%$ FBS. After $24 \mathrm{~h}$, the conditioned medium was collected, and as for TGF- $\beta$, protease inhibitors were added, samples were centrifuged, and supernatant solutions were concentrated and stored at $-20^{\circ} \mathrm{C}$. For Northern blot analyses, cocultures or their individual components were prepared and after interaction among HAEC, HASMC, and monocytes, the media were removed, cell layers were washed with PBS, $\mathrm{pH} 7.4$, and total cellular RNA was isolated by lysis of cell layers in guanidinium isothiocyanate, phenolchloroform extraction, and precipitation (23). $10 \mu \mathrm{g}$ of each RNA preparation from cocultures or components was denatured and subjected to electrophoresis on a $1.2 \%$ formaldehyde agarose gel. This was followed by blotting onto nylon filters and UV cross-linking (24). TGF- $\beta$ Northern analysis was performed as described (24). The blots were then washed at a final stringency of $0.5 \times \mathrm{SSC} / 0.1 \% \mathrm{SDS}$, at $65^{\circ} \mathrm{C}(1 \times \mathrm{SSC}$ : $0.15 \mathrm{M} \mathrm{NaCl} / 15 \mathrm{mM}$ sodium citrate), and were autoradiographed. For connexin Northern analyses, the blots were prehybridized for $1 \mathrm{~h}$ at $65^{\circ} \mathrm{C}$, in $20 \mathrm{ml}$ solution of $0.75 \mathrm{M} \mathrm{NaCl}, 0.15 \mathrm{M}$ Tris $\cdot \mathrm{HCl}$ (pH 8.0), 10 mM EDTA, 0.1\% Ficoll/0.1\% polyvinylpyrolidone/0.1\% SDS, 0.1\% bovine serum albumin. The buffer was then discarded and the hybridization to CDNA probes for connexins 43 and 32 was performed in the same buffer for $16 \mathrm{~h}$ at $55^{\circ} \mathrm{C}$. The probes were previously labeled to a specific activity of $\sim 10^{9} \mathrm{cpm} / \mu \mathrm{g}(25)$ and $2 \times 10^{6} \mathrm{cpm} / \mathrm{ml}$ was used for each blot. The blots were then washed for $30 \mathrm{~s}$ with $100 \mathrm{ml}$ of $2 \times$ SSC, were washed twice with $500 \mathrm{ml}$ of $1 \times$ SSC for 30 min each at room temperature and twice with $0.5 \times \mathrm{SSC}$ for $30 \mathrm{~min}$ each at $55^{\circ} \mathrm{C}$, and were autoradiographed. The autoradiographs were scanned by laser densitometry, signals were quantitated, and those for connexin were normalized for $\alpha$-tubulin values.

Bioassays. The biological activity due to CSFs in the conditioned media of the cocultures or the components (i.e., equivalent numbers of HAEC or HASMC cultured separately) was determined by the colony formation assay employing mouse bone marrow cells for M-CSF (26) and human bone marrow cells for GM-CSF (27). For calculating the CSF activity in the conditioned media from cell cultures, the number of colonies produced by medium from collagen alone was considered as background and was subtracted from values obtained for medium from cell cultures. Bioassays for TGF- $\beta$ based on anchorage-independent growth and colony formation of AKR-2B cells in soft agar were performed as described $(28,29)$.

Metabolic labeling of cells. HAEC cultured on collagen (EC/COL) on a filter (0.6- or $4.5-\mathrm{cm}^{2}$ surface area), collagen layered on HASMC (COL/SMC) on a filter, or the combination (EC/COL/SMC) on a filter were metabolically labeled with $\left.{ }^{35} \mathrm{~S}\right]$ methionine $(200 \mu \mathrm{Ci} / \mathrm{ml})$ for $2 \mathrm{~h}$ in methionine-free medium, or with $\left[{ }^{14} \mathrm{C}\right]$ proline $(20 \mu \mathrm{Ci} / \mathrm{ml})$ for $2 \mathrm{~h}$ in proline-free medium in the presence of $2.5 \% \mathrm{HI}$ serum. The culture media were collected and the protease inhibitors $(30)$ were added. The cultures were then washed with medium containing $40 \mu \mathrm{M}$ nonradioactive methionine and incubated in this medium for $2 \mathrm{~h}$. The chase medium was collected, protease inhibitors were added, the medium was centrifuged at $350 \mathrm{~g}$, and the supernatants were kept at $-20^{\circ} \mathrm{C}$. The cell layers on filters were washed three times with phos- 
phate-buffered saline (PBS) pH 7.4, and $1.0 \mathrm{ml}$ of buffer A (30) was added to each of the filters which were subsequently kept at room temperature for $30 \mathrm{~min}$. The cell lysates together with matrices were quantitatively transferred to microcentrifuge tubes containing protease inhibitors and kept at $-20^{\circ} \mathrm{C}$.

Immunoprecipitation of radiolabeled fibronectin and collagen. Before immunoprecipitation, the thawed media were precleared with protein A-Sepharose. Trichloroacetic acid (TCA)-precipitable counts were then determined (31). To equal TCA-precipitable counts (50-200 $\mu \mathrm{l})$ from each sample, was added $10 \mu \mathrm{l}$ of anti-human fibronectin IgC fraction or $2 \mu \mathrm{l}$ of anti-human collagen IgG fraction and the volume was adjusted to $500 \mu \mathrm{l}$ with buffer $\mathrm{A}$. Immunoprecipitation and gel electrophoresis were then carried out as described (30-32). The gels were fixed, treated with Enhance, and autoradiographed. The levels of the radiolabeled and immunoprecipitated (RI) fibronectin or collagen were determined by direct counting of $10-\mu 1$ aliquots of RI samples before polyacrylamide gel electrophoresis (PAGE), by laser densitometry of the autoradiograms obtained after PAGE, and by cutting out of the gels of the areas corresponding to RI fibronectin or collagen bands on autoradiograms followed by counting for their ${ }^{35} \mathrm{~S}$ or ${ }^{14} \mathrm{C}$ content.

Addition of monocytes to cocultures. EC/COL, COL/SMC, or EC/ $\mathrm{COL} / \mathrm{SMC}$ on filters were exposed on the basal side (side opposite to the cells), to the reference chemoattractant $n$-formyl-methionyl-leucylphenylalanine (FMLP) at a concentration of $10^{-7} \mathrm{M}$ for $60 \mathrm{~min}$ at $37^{\circ} \mathrm{C}$. This concentration was previously found to be optimal for maximum monocyte chemotaxis in this system (19). Human monocytes (1 $\times 10^{6} \mathrm{cells} / \mathrm{ml} \cdot \mathrm{cm}^{2}$ ) were presented to the apical side of the cell layers on filters and the incubation was continued for $60 \mathrm{~min}$. This medium contained $2.5 \% \mathrm{HI}$ autologous serum. After this step of incubation, the medium containing the nonadherent leukocytes was removed. The cell layers on the filters were washed with $1 \mathrm{ml}$ of IDME at $37^{\circ} \mathrm{C}$ to remove the cells that were loosely attached to the endothelial monolayer. Human monocytes were also presented to filters with collagen matrix alone and exposed on the opposite side of the filter to FMLP at a $10^{-7}$ $M$ concentration. The cultures on the filters were maintained in IDME containing 30\% $\mathrm{HI}$ autologous serum, supplements, and antibiotics (19) for up to $5 \mathrm{~d}$. Cultures were metabolically labeled with $\left[{ }^{35} \mathrm{~S}\right]-$ methionine or with $\left[{ }^{14} \mathrm{C}\right]$ proline $1-5 \mathrm{~d}$ after the addition of monocytes, and the levels of fibronectin and collagen were determined. In addition to the procedure described for immunoprecipitation of fibronectin or collagen, a simple immunoadsorbtion assay was developed, based on reported procedures (33), for rapid detection of the levels of radiolabeled fibronectin. In this assay antihuman fibronectin antibody (IgG fraction, $15.9 \mathrm{mg} / \mathrm{ml}$ ) was diluted 1:1,000 in $0.1 \mathrm{M}$ carbonate buffer, $\mathrm{pH}$ 9.6. Wells in microtiter plates were coated with $150 \mu \mathrm{l}$ of diluted antibody. Wells with nonimmune IgG or with no antibody were included as controls. The plates were incubated at $4^{\circ} \mathrm{C}$ for $16 \mathrm{~h}$. The wells were then washed three times in a PBS/Tween-20 solution (33). The antibody solution was aspirated and $10 \mu \mathrm{l}$ samples to be tested were diluted 1:10 (vol/vol) in PBS supplemented with BSA $(5 \mathrm{mg} / \mathrm{ml})$ and were applied to wells in duplicates of $100 \mu \mathrm{l}$ each. Wells with excess nonradioactive fibronectin were also included as controls. After incubation for $16 \mathrm{~h}$ at $4^{\circ} \mathrm{C}$ the plates were washed five times with PBSTween and were rinsed five times with distilled water. The wells were cut out, and the ${ }^{35} \mathrm{~S}$ content was determined. In addition to the standard gel electrophoresis procedure used, in later stages of these studies a tricine mini-gel system (34) was employed for the analyses of RI fibronectin, which was found to resolve the fibronectin into a pattern that was spatially identical but qualitatively superior to that obtained by polyacrylamide gels containing $8 \mathrm{M}$ urea. In addition the mini-gel system, required only one-third the sample size, and one-tenth the length of time compared to the standard SDS-PAGE systems. In order to determine the level of fibronectin in the conditioned medium of the same cocultures at several time intervals without ${ }^{35} \mathrm{~S}$ radiolabeling, an established ELISA for fibronectin (33) was used.

Other procedures. Measurement of cell protein content was done by the method of Lowry et al. (35), and determination of cell number was carried out by standard procedures (21).

\section{Results}

Growth factor activity. Using the HAEC and HASMC from the same heart donor, multilayer cocultures were established, conditioned media were obtained, and the biological activities of the CSFs were determined. For M-CSF, after subtracting the number of colonies produced by medium incubated with collagen alone, the medium conditioned by cocultures was found to produce 2.3 -fold more colonies than could be accounted for by those from the same number of HAEC and HASMC cultured separately (Fig. $1 \mathrm{~A}$ ). Preincubation of the conditioned medium with neutralizing antibody to M-CSF prevented colony formation, indicating that the bioactivity was indeed due to M-CSF (Fig. $1 A$ ). The coculture medium also contained 3.7fold more GM-CSF bioactivity compared to the sum of the activities in the medium from HAEC and HASMC (Fig. $1 B$ ). Preincubation of the conditioned medium with neutralizing antibody to GM-CSF prevented colony formation, indicating that the bioactivity was in fact due to GM-CSF (Fig. $1 B$ ).

Northern analyses demonstrated that both the HAEC and HASMC contained mRNA for TGF- $\beta$. The levels of mRNA from the cocultures were at least equal to the sum of those from the components (data not shown). AKR-2B cells form colonies specifically in response to TGF- $\beta$ (28). As demonstrated in Fig. $1 C$, the addition of transiently acidified media from the components did not significantly stimulate colony formation but addition of transiently acidified media from the coculture had a marked stimulatory effect (up to 5.1-fold over the sum of the components). The colony formation was inhibited in the presence of neutralizing antibody to TGF- $\beta$ but not when an irrelevant antibody was added (Fig. $1 C$ ). In contrast to previous reports of cocultures of bovine $\operatorname{EC}$ and $\operatorname{SMC}(7,8)$ the increased TGF- $\beta$ activity seen in the cocultures established for the present studies was entirely latent (i.e., required transient acidification for expression; data not shown). When, however, conditions employed by Antonelli-Orlidge and colleagues (7), where EC and SMC are grown not as multilayers of confluent EC and SMC but as mixed cultures were used, the growth of HAEC was inhibited by coculture medium indicating the presence of active TGF- $\beta$ in these coculture media (data not shown).

Matrix components. The results of immunoprecipitation of radiolabeled fibronectin from the media and cell lysates of the components and the coculture are demonstrated in Fig. 2. In each instance equal TCA-precipitable counts were applied to each lane in the gels. There was a marked increase (up to 3.2fold for the medium and 2.8-fold for the cells) in the incorporation of $\left[{ }^{35} \mathrm{~S}\right]$ methionine into RI fibronectin in the coculture $(E$ $+S$, lane 3; arrow) as compared to the components ( $E$, lane 1 ; $S$, lane 2). Addition of neutralizing antibody to TGF- $\beta$ to the cultures produced significant increases in the levels of fibronectin in the culture medium (up to 2.2- and 5.1-fold, from EC and SMC, respectively, panel $A$ ) and in the cell layers (up to 2.9-fold and 3.2-fold from EC and SMC respectively, panel $B$ ); compare lanes 4 and 1 and lanes 5 and 2 . Addition of the antibody to cocultures, however, resulted in a $73 \%$ decrease in the RI fibronectin levels in the culture medium and less of a decrease $(48 \%)$ in the cell lysates from the coculture (compare lanes 6 and 3). Immunoprecipitation of media and cell lysates from coculture $(E+S)$ using a nonimmune $\operatorname{IgG}(N I)$ produced a much reduced signal for RI fibronectin levels (6\% and $9 \%$ of controls in the media and in the cell layers, respectively); com- 

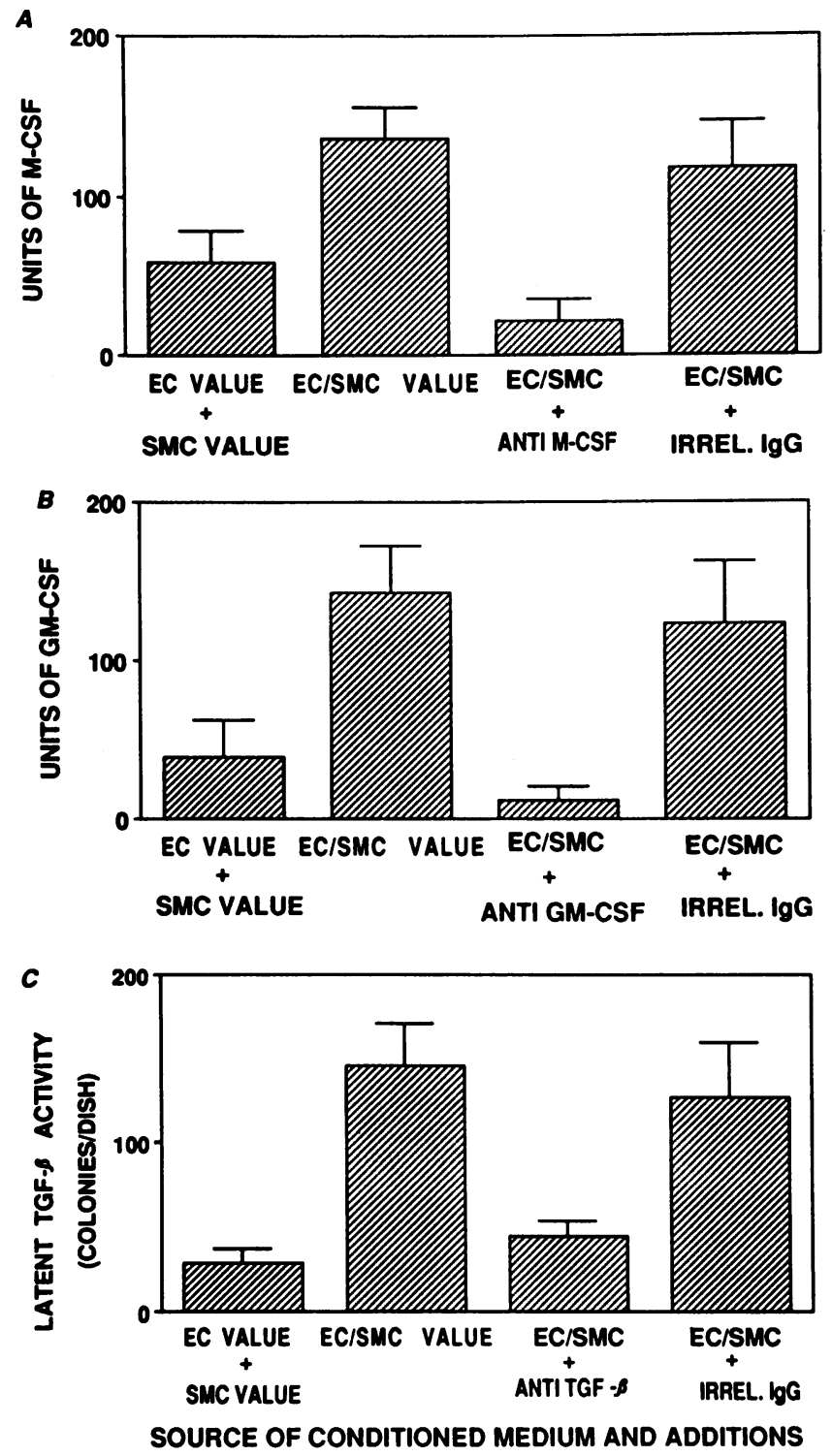

Figure 1. Increased levels of growth factors in cocultures of human artery wall cells. Conditioned media from EC/COL, COL/SMC, and the cocultures, $\mathrm{EC} / \mathrm{COL} / \mathrm{SMC}$, were concentrated 10 -fold and were tested in CSF or TGF- $\beta$ assays. The collagen background was subtracted from all of the values and the sum of the values for separate cultures of EC and SMC is compared with the value for EC/SMC coculture. In these assays the colony formation in soft agar was allowed to proceed for 7-10 d after which the colonies containing 50 or more cells were counted. Antibodies to M-CSF, GM-CSF, or irrelevant IgG were preincubated with the media and were added to some of the cultures, designated $E C / S M C+A N T I M-C S F, E C / S M C$ $+A N T I G M-C S F$, or $E C / S M C+I R R E L$. IgG. respectively. $(A)$ Values obtained using a mouse bone marrow assay for M-CSF bioactivity. $(B)$ Results obtained employing a human bone marrow assay for GM-CSF bioactivity. The values shown are the mean \pm SD of triplicate samples from two (M-CSF) and three (GM-CSF) assays. The values are given in units of CSF. One unit of CSF is the amount of the growth factor that produces one colony for each $10^{5}$ cells plated. For the TGF- $\beta$ bioassay, conditioned media were concentrated, transiently acidified, and presented to AKR-2B cells in soft agar (panel $C$ ). To some of the media $(E C / S M C+A N T I T G F-\beta)$, neutralizing antibody to TGF- $\beta, 50 \mu \mathrm{g} / \mathrm{ml}$, and to some others $(E C / S M C+I R R E L$. $I g G), 50 \mu \mathrm{g} / \mathrm{ml}$ of an irrelevant IgG were added. Colonies containing pare lanes 7 and 3. Immunoprecipitation of samples from cocultures in the presence of excess $(75-100 \mu \mathrm{g} /$ tube) nonradioactive fibronectin also produced markedly reduced signals for RI fibronectin levels, down to $11 \%$ and $16 \%$ of controls in the media and in the cell layers, respectively (compare lanes 9 and 3), indicating the authenticity of the fibronectin signal. When HAEC and HASMC were separated by a filter with $0.2-\mu \mathrm{m}$ pore diameter in the same chamber and medium $(E+S$, filter) permitting access of media but preventing ECSMC contact, there was a marked decrease (down to $9 \%$ and $37 \%$ of controls) in RI fibronectin levels in the media and in the cell layers, respectively (compare lanes 8 and 3 ).

The results of immunoprecipitation of type I collagen from the medium and cell lysates from cocultures and components is shown in Fig. 3. The coculture $(E+S)$ demonstrated collagen levels that were higher (2.7-fold in the media, panel $A$ and 2.4-fold in the cell layers, panel $B$ ) than could be accounted for by the sum of the contributions of the components $(E+S$, lane 3 vs. $E$, lane $l$ or $S$, lane 2 , arrow). The presence of neutralizing antibody to TGF- $\beta$ (+antiTGF- $\beta$, lanes 4-6) reduced the collagen levels in the coculture medium (by $43 \%$ ) and in the cell layers by $47 \%$ but markedly enhanced the amount of collagen in HASMC cultures (1.9-fold for the media and 2.3-fold for the cell layers; compare lanes 5 and 2 . The presence of a filter with $0.2-\mu \mathrm{m}$ pore diameter between the HAEC and HASMC $(E+S$, filter, lane 8 ) which permitted access of the media but prevented EC-SMC contact, reduced the collagen levels by $79 \%$ in the medium from cocultures $(E+S)$ and by $63 \%$ in the cell layers (compare lanes 8 and 3). The addition of excess nonradioactive collagen to the samples before incubation with anticollagen $(E+S, C O L$, lane 9$)$ produced markedly reduced signals $(9 \%$ and $13 \%$ of controls for the media and the cell layers, respectively); compare with lane 3 . Incubation of samples with nonimmune IgG $(E+S, N I$, lane 7) resulted in markedly reduced levels of RI collagen (down to $4 \%$ and $12 \%$ of controls for the media and the cell layers, respectively; compare with lane 3), indicating the authenticity of the collagen signal.

Addition of human blood monocytes $(M)$ to the cocultures (ES) produced a dramatic increase (up to 22 -fold) in the fibronectin levels in the culture media (Fig. $4 \mathrm{~A}$, arrow). The increase in type I collagen produced by the interaction of monocyte-macrophages and the cells of the artery wall was less pronounced (1.9-fold) (Fig. $4 \mathrm{~B}$ ).

The results of immunoradioassay for fibronectin (Fig. $5 \mathrm{~B}$ ) confirmed the results generated by laser densitometry of the autoradiograms obtained after gel electrophoresis of immunoprecipitates (Fig. $5 A$ ), which were both similar to the results obtained by direct determination of radioactivity in aliquots of immunoprecipitates before applying to gels (data not illustrated). There was complete agreement between the results in Fig. 5 and those obtained by cutting the relevant bands out of the gels, extracting the RI fibronectin, and counting their ${ }^{35} \mathrm{~S}$ content (data not shown).

Gap junction protein $m R N A$. Northern analyses demonstrated that interaction of HAEC and HASMC resulted in lev-

more than 50 cells were counted after $10 \mathrm{~d}$ of incubation. The values shown are the mean \pm SD of values from triplicate wells in three AKR-2B bioassays. 
$A$

$$
\begin{array}{lllllll} 
& \mathrm{S} & \mathrm{E}+\mathrm{S} & \mathrm{E} & \mathrm{S} & \mathrm{E}+\mathrm{S} & \mathrm{E}+\mathrm{S}
\end{array}
$$

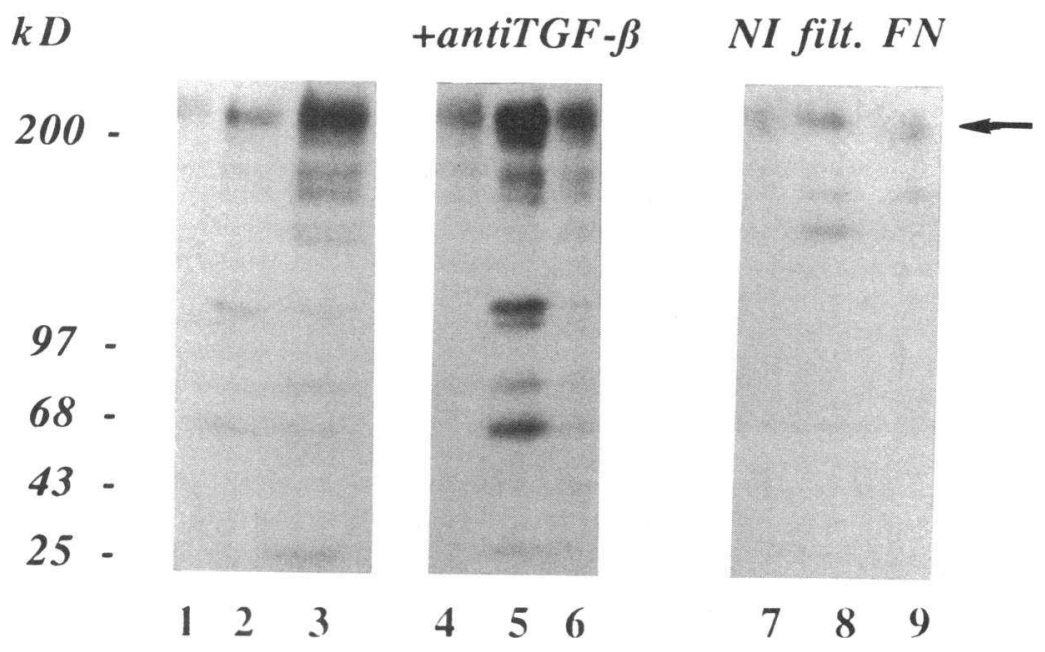

B

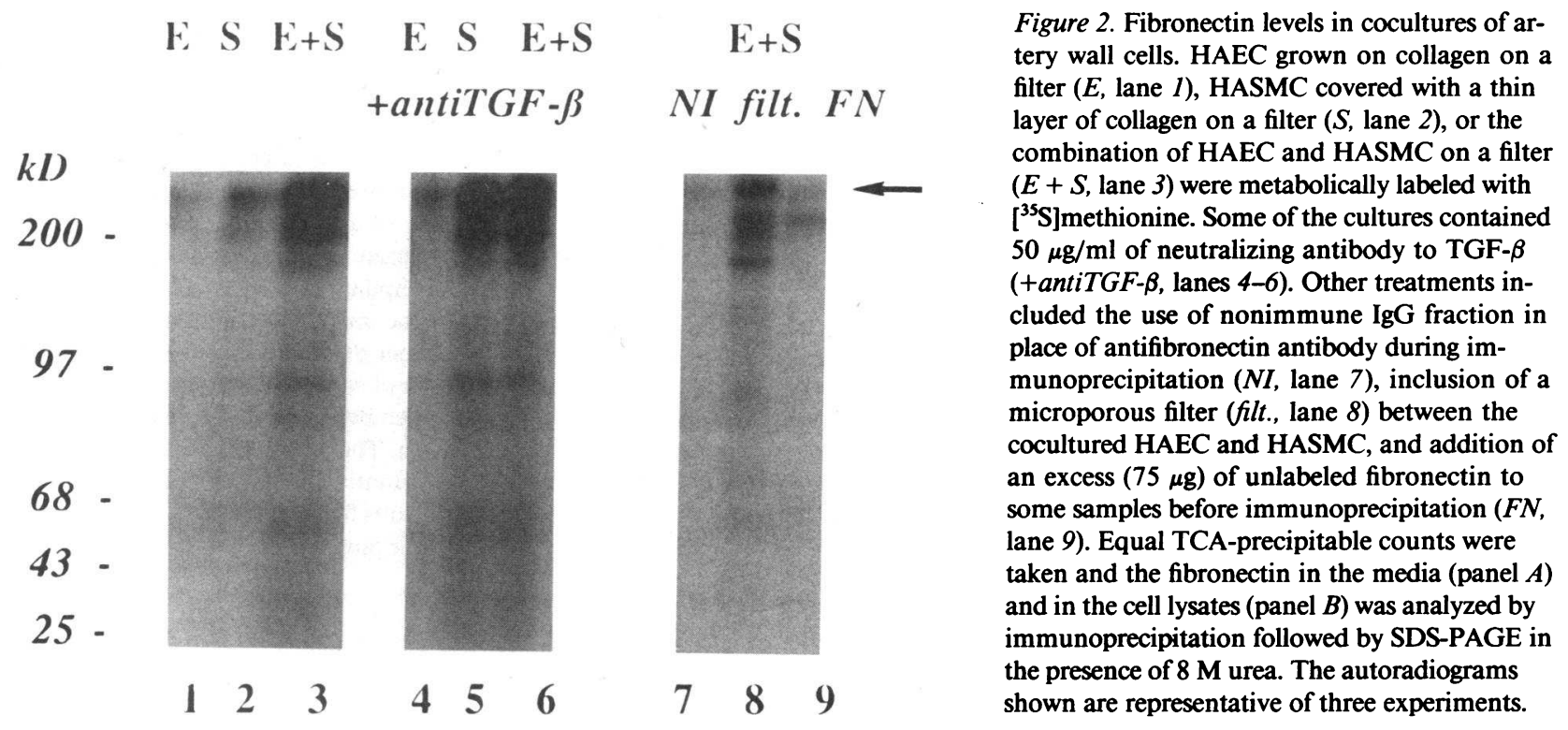

els of mRNA for the gap junction protein connexin43 that were 2.7-fold higher than could be accounted for by the sum of the contributions of the components (Fig. 6, compare ES, lane 3 vs. $E$, lane 1 and $S$, lane 2 ). There was no detectable signals for mRNA for connexin32 (data not shown). Interaction of human monocytes with HAEC produced enhanced levels of mRNA for connexin 43 that were 3.7-fold higher than could be accounted for by the contribution of monocytes and HAEC cultured separately (compare $M E$, lane 5 with $E$, lane 1 and $M$, lane 4). Interaction with HASMC induced an increase in message for connexin 43 , which was 2.1 -fold that of the combined values for monocytes and HASMC in separate cultures (compare $M S$, lane 6 with $S$, lane 2 and $M$, lane 4). Interaction of monocytes with cocultures of HAEC and HASMC resulted in a marked increase in the induction of message for connexin 43 to levels 2.8-fold greater than the combined values for culture of monocytes and coculture of EC and SMC (compare MES, lane 7 with $M$, lane 4 or $E S$, lane 3).

$I L-1$ and IL-6. Addition of neutralizing antibody to IL-1 to cocultures of EC and SMC did not change the fibronectin levels (Fig. 7). Presence of neutralizing antibody to IL-1 or neutralizing antibody to IL- 6 during the interaction of monocytes with cocultures of HAEC and HASMC resulted in $45 \%$ and $67 \%$ reduction in the levels of immunoreactive fibronectin in the culture media, respectively (Fig. 7), whereas the presence of irrelevant IgG did not significantly change the fibronectin levels (Fig. 7). Presence of antibody to IL-1 together with antibody to IL-6 did not increase the blocking effect of anti-IL-6 alone (data not illustrated). Neutralizing antibodies to M-CSF and GM-CSF did not produce a significant change in the increased 


\section{$\begin{array}{llllllll}\mathbf{E} & \mathbf{S} & \mathbf{E}+\mathrm{S} & \mathbf{E} & \mathbf{S} & \mathbf{E}+\mathrm{S} & & \mathbf{E}+\mathrm{S}\end{array}$ tantiTGF- $\beta$ NI filter $C O L$}

\section{$K D$}

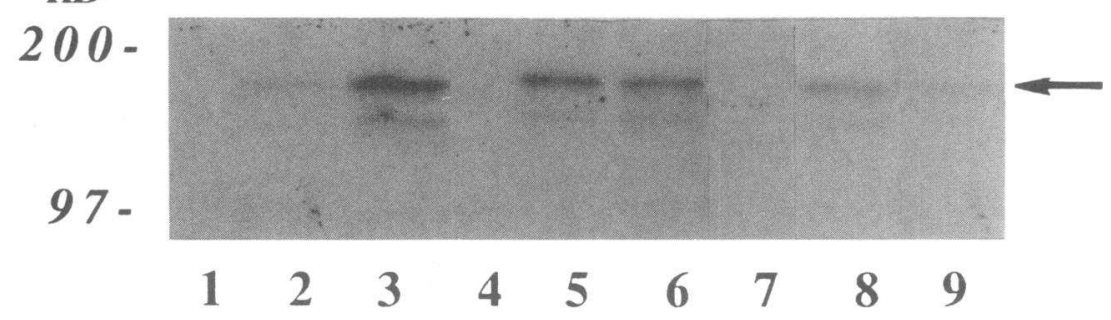

B

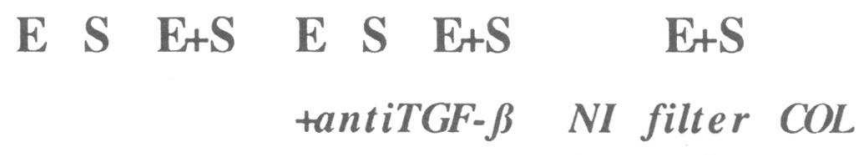

\section{$k D$}

200

97 -
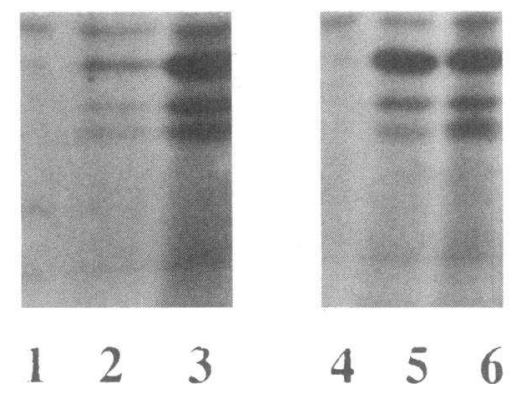

456

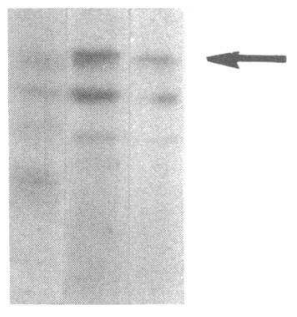

$\begin{array}{lll}7 & 8 & 9\end{array}$
Figure 3. Collagen levels in cocultures of the artery wall cells. HAEC grown on collagen on a filter ( $E$, lane 1$)$ HASMC covered with a thin layer of collagen on a filter ( $S$, lane 2 ) or the combination of the HAEC and HASMC on a filter $(E+S$, lane 3$)$ were metabolically labeled with $\left[{ }^{14} \mathrm{C}\right]$ proline. Neutralizing antibody to TGF- $\beta, 50 \mu \mathrm{g} / \mathrm{ml}$, (+antiTGF- $\beta$, lanes 4-6) was added to some of the cultures. Other treatments included the use of nonimmune IgG fraction in place of anticollagen (NI, lane 7), inclusion of a microporous filter (filter, lane 8 ) between the cocultured HAEC and HASMC, and addition of an excess $(75 \mu \mathrm{g})$ of nonradioactive collagen to some samples prior to immunoprecipitation ( $C O L$, lane 9 ). Collagen type I in the medium (panel $A$ ) and the cell layers (panel $B$ ) was analyzed by immunoprecipitation of equal TCA-precipitable counts followed by SDS-PAGE in the presence of $8 \mathrm{M}$ urea. The autoradiogram shown here is representative of two separate experiments. $(A)$ Results for culture media; $(B)$ results for cell layer plus matrix. levels of fibronectin produced by the interaction of monocytes and cocultures of EC and SMC (data not shown).

\section{Discussion}

In normal arteries very few SMC are found in the subendothelial space (1). Higher numbers of SMC in association with EC have been observed in experimental atherosclerosis (2) and in atherosclerotic human arteries $(2,36)$. Accumulating evidence indicates that substantial direct physical contact and interaction occurs between EC and SMC in vitro $(4,6-8,37,38)$ and in vivo (38-42). In our studies, the interaction in vitro between HAEC and HASMC produced a two- to fourfold increase in M-CSF and GM-CSF levels in the culture media (Fig. 1). MCSF can support the growth and survival of monocyte-macrophages in vitro even in the absence of serum growth factors (43). From the study of autopsy specimens of human coronary arteries, Stary (36) speculated that many of the monocytemacrophages in the subendothelial space would have died unless their survival had been supported by growth factors (36).
M-CSF produced by the interaction of EC and SMC could potentially act as one such factor. GM-CSF could be another one. GM-CSF has been shown to prolong the survival, differentiation, proliferation and development of responsive cells in vitro (43). Lang et al. (44) demonstrated that the expression of GM-CSF gene in transgenic mice led to the accumulation of monocyte-macrophages in tissues such as eyes, striated muscle, and in peritoneal cells expressing this gene and resulted in substantial tissue damage (44).

Cocultures of HAEC and HASMC under the conditions employed in the present study led to a marked increase in latent TGF- $\beta$ (Fig. $1 C$ ). In contrast to the results of AntonelliOrlidge et al. (7) and Sato and colleagues $(8,48)$ all of the activity in our culture media was latent. Since we were able to reproduce the results of Antonelli-Orlidge by using growtharrested HASMC and culturing HAEC directly mixed with them following the exact conditions described (7), we cannot ascribe the different results to the difference in cell types. It seems more likely that the architecture of our culture model (which is more similar to that of artery wall in vivo) favored the 
A

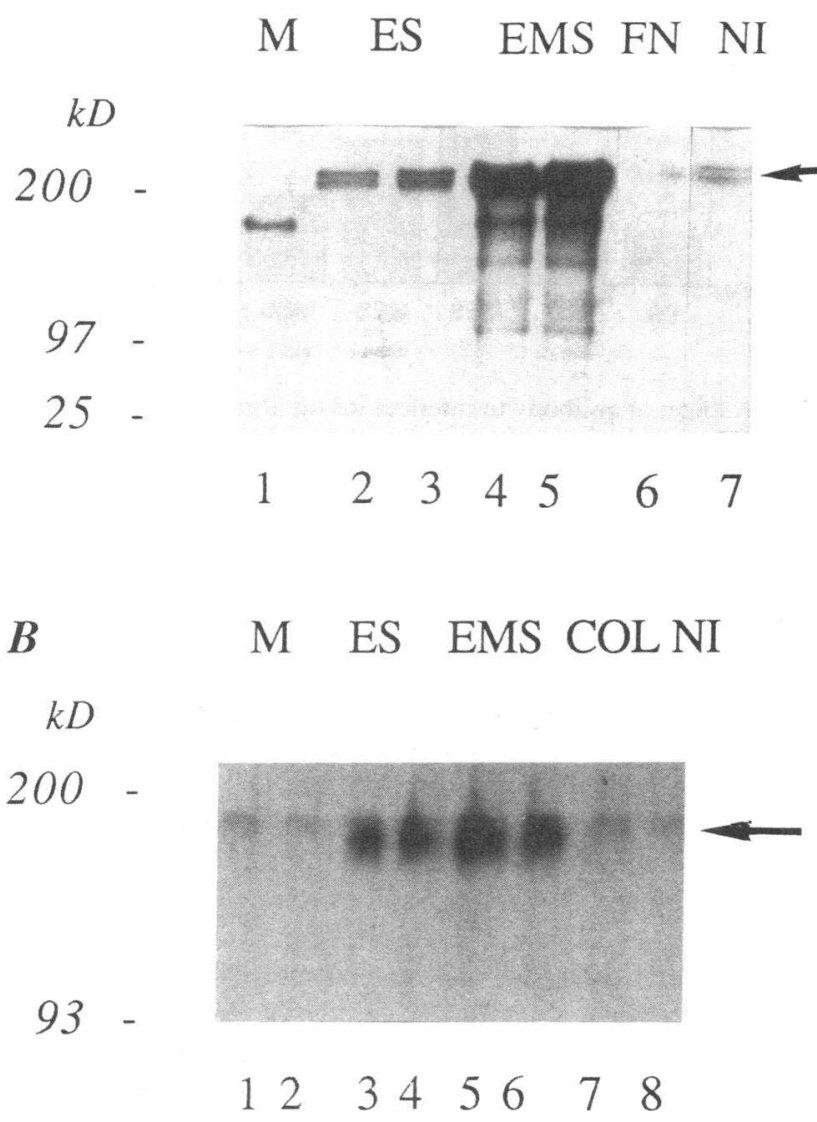

Figure 4. Effect of monocyte-macrophages on RI fibronectin and collagen levels produced by artery wall cells. Cocultures of HAEC and HASMC on microporous filters ( $E S$, duplicate lanes 2 and 3 in $A$; duplicate lanes 3 and 4 in $B$ ) were exposed on the basal side, to a $10^{-7}$ $\mathrm{M}$ solution of FMLP at $37^{\circ} \mathrm{C}$ for $1 \mathrm{~h}$. Human monocytes $\left(1 \times 10^{6}\right.$ cells $/ \mathrm{ml} \cdot \mathrm{cm}^{2}$ ) were presented to filters alone ( $M$, lane 1 in $A$; duplicate lanes 1 and 2 in $B$ ) or to cocultures of HAEC and HASMC ( $E M S$, duplicate lanes 4 and 5 in $A$; duplicate lanes 5 and 6 in $B$ ). After $60 \mathrm{~min}$ at $37^{\circ} \mathrm{C}$ the media containing the nonadherent monocytes were removed. Subsequently the cultures were maintained in IDME containing $30 \% \mathrm{HI}$ autologous serum at $37^{\circ} \mathrm{C}$ for $2 \mathrm{~d}$. The cultures were pulse labeled with $\left[{ }^{35} \mathrm{~S}\right]$ methionine $(A)$ or with $\left[{ }^{14} \mathrm{C}\right]-$ proline $(B)$ as described in Methods. Equal TCA-precipitable counts were taken and fibronectin $(A)$ or collagen $(B)$ were immunoprecipitated using the corresponding specific antibody (lanes $1-6$ in $A$; lanes $1-7$ in $B)$ or nonimmune serum $(N I$, lane 7 in $A$; lane 8 in $B)$ or presence of excess nonradioactive ligand ( $75 \mu \mathrm{g}$ fibronectin, $F N$, lane 6 in $A ; 75 \mu \mathrm{g}$ collagen, $C O L$, lane 7 in $B$ ). Samples were analyzed using $10 \%$ tricine mini-gels $(A)$ or $7.5 \%$ polyacrylamide gels containing $8 \mathrm{M}$ urea $(B)$. The autoradiograms presented here are representative of seven experiments (for fibronectin) and two experiments (for collagen).

production of latent TGF- $\beta$. Histological studies of the multilayer cocultures have demonstrated the presence of a continuous and confluent endothelial monolayer on top of a thin layer of extracellular matrix (1-2 $\mu \mathrm{m}$ thick) over confluent layers of SMC (19). After 2-3 d in culture EC were often found to make frequent direct physical contacts with the underlying SMC (unpublished observations).
It is known that TGF- $\beta$ can have different and complex effects on the same cells under different conditions and can be under autocrine regulation (45-48). As shown in Figs. 2 and 3, neutralizing antibody to TGF- $\beta$ stimulated HAEC and HASMC to produce fibronectin and collagen type I when the cells were cultured separately. Inclusion of the same antibody together with the same number of HAEC and HASMC in coculture led to a modest decrease in the production of these molecules. The increase in RI fibronectin and collagen in the presence of TGF- $\beta$ antibody in HAEC and SMC is in contrast to the well-known effect of TGF- $\beta$ on various cell types where this growth factor induced fibronectin and collagen message expression or protein formation $(47,49-51)$. The state of growth of the cells and the extent of cell-cell contact (51), the composition of extracellular matrix and its activating potential

$\boldsymbol{A}$

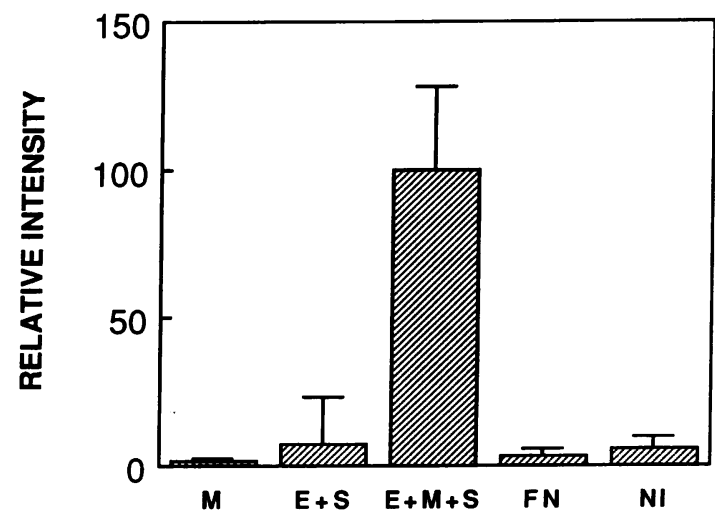

B

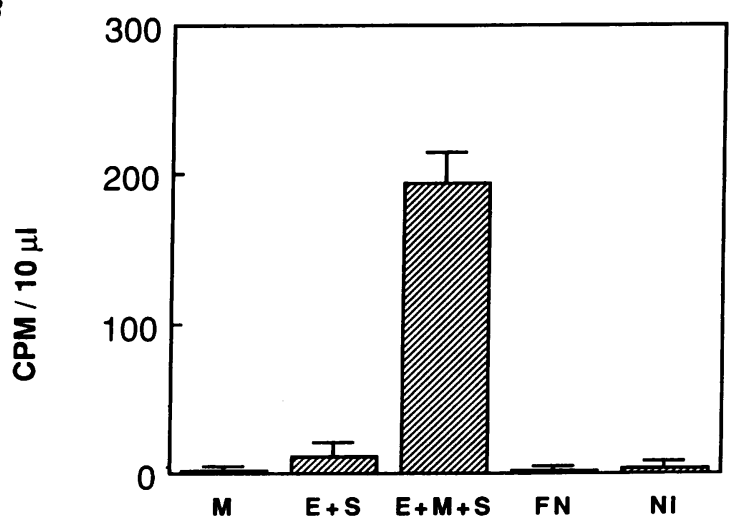

SOURCE OF MEDIUM AND ADDITIONS

Figure 5. Determination of levels of radiolabeled fibronectin. $(A)$ The autoradiograms obtained from SDS gels were analyzed by a laser densitometer, and triplicate readings were obtained and utilized to calculate mean \pm SD for signals corresponding to monocytes $(M)$, cocultures of HAEC and HASMC $(E+S)$, cocultures with monocytes $(E+M+S)$, using nonimmune IgG $(N I)$ or added nonradioactive fibronectin $(F N)$. (B) 10- $\mu$ l samples of the chase media following the metabolic labeling of the cocultures $(E+S)$ with or without monocytes $(M)$ were used in the immunoradioassay developed for human fibronectin as described in Methods. The values express mean \pm SD of triplicate samples and the results are representative of three experiments. 
(52), the TGF- $\beta$ receptor expression and its interaction with matrix and modulation of TGF- $\beta$ binding to cell (53), the level of TGF- $\beta$ inhibitor and the composition of matrix $(54,55)$, and the combination of other growth factors $(56,57)$ have all been reported to affect the cellular responses to TGF- $\beta$. According to Sporn and Roberts (58), this peptide growth factor can have both growth stimulatory and inhibitory activity in a single cell, depending on the context of the other signal molecules present. Streuli and Bissell (55) found that, in mammary epithelial cells grown on plastic, there was a dramatic induction of fibronectin message, while the induction was inhibited in the same cells grown on collagen gel. The authors noted that soluble factors such as TGF- $\beta$ are increased and/or activated and mediate changes in matrix expression to varying degrees in cells cultured on different substratum (55). Regardless of the role of TGF- $\beta$, the coculture of HAEC and HASMC clearly led to an increase in the production of both fibronectin and collagen which depended on close physical approximation of the two cell types (Figs. 2 and 3). The increased induction of the gap junction protein connexin43 in cocultures of EC and SMC (Fig. 6) indicates the possibility of increased junctional communication and interaction between the EC and SMC in these cocultures $(5,10,59)$. In the present study, addition of human monocytes from nine different donors (but not from three others) to the cocultures amplified the production of the extracellular matrix molecules (Figs. 4, 5, and 7). Addition of monocytes to cocultures also produced a marked induction of connexin 43 raising the possibility of increased direct heterotypic cellular communications.

Upon activation, monocytes demonstrate markedly increased activities for numerous factors including for IL-1 (60). We have observed that during the process of monocyte transmigration into the subendothelial space of the coculture the cells acquire the typical appearance of spread monocytes suggesting the activation of these cells (unpublished observations, and reference 61). Injection of IL-1 into rats has been reported to produce elevated serum levels of fibronectin (62). Leukocyte interleukins have also been reported to induce cultured EC to produce a highly organized pericellular matrix (63). IL-1 induces IL-6 in certain cell types (64). Hagiwara and co-workers

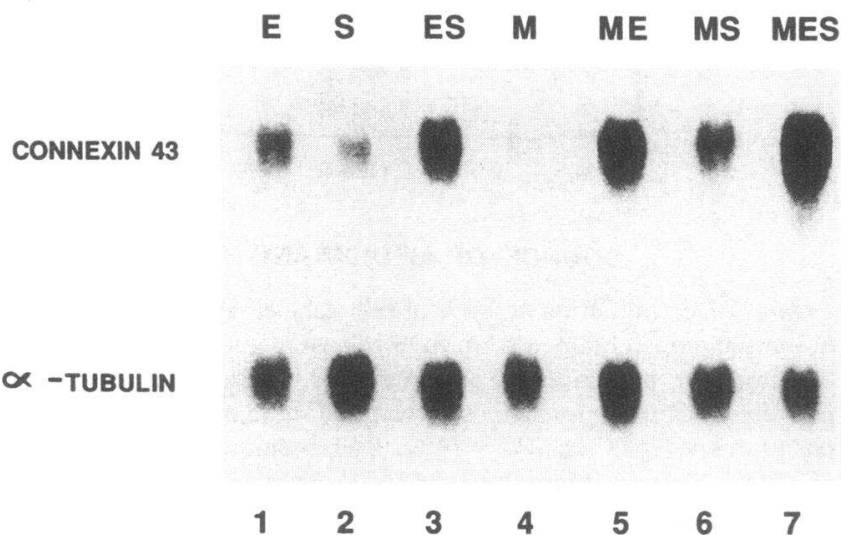

Figure 6. Connexin 43 mRNA. Cocultures of artery wall cells with $2 \mathrm{~h}$ of exposure to monocytes and cultures of components were used to isolate total cellular RNA. After electrophoresis and transfer to nylon filters, samples were probed with labeled cDNA for connexin 43. The autoradiogram shown is from one such hybridized Northern blot.

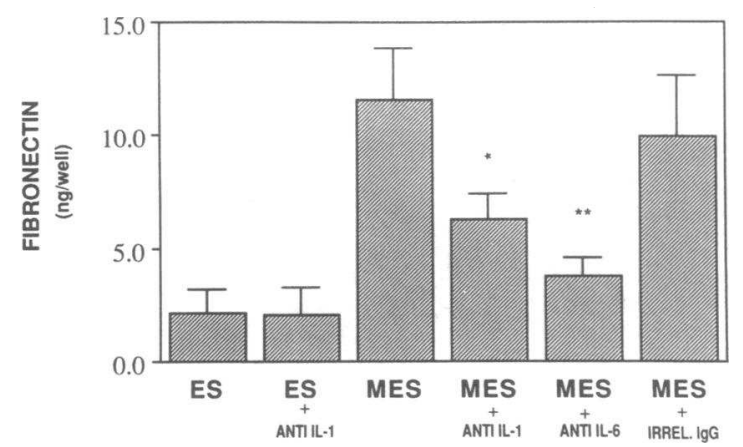

Figure 7. Effect of antibody to interleukins on fibronectin levels. Cocultures of artery wall cells with monocytes and cultures of components were prepared and the level of fibronectin in the culture supernatants was determined in an ELISA. Some cultures received $2 \mu \mathrm{g} / \mathrm{ml}$ of neutralizing antibody to each of IL-1 $\beta$ (ES + ANTI IL-1, MES $+A N T I I L-1)$, or IL-6 (MES + ANTI IL-6), or nonimmune IgG $(M E S+I R R E L . I g G)$. The values are mean \pm SD of three separate experiments. ${ }^{*} P<0.04 ;{ }^{* *} P<0.027$.

(65) demonstrated that monocytes stimulated by IL-1 produced increased levels of IL-6 and that in turn resulted in elevated levels of fibronectin in cultured hepatocytes. Lanser and Brown (66) have shown that increased fibronectin production by rat hepatocytes exposed to conditioned medium from stimulated monocytes is due to IL-6. In the present study, the signifcant inhibition of monocyte-induced increase in fibronectin levels in cocultures of artery wall cells by neutralizing antibodies to IL-1 and to IL- 6 strongly suggests the involvement of these cytokines in the monocyte-artery wall cell interactions.

Both fibronectin and collagen type I have been implicated in atherogenesis (67). Increased levels of fibronectin were seen in rabbit aorta 4 wk after cholesterol feeding (68). Moreover, substantial levels of fibronectin have been observed in the extracellular matrix of fatty streaks and in some areas of fibrous plaque containing large numbers of subendothelial cells in human arteries (69). Similarly, increases in collagen have been shown in several experimental models of atherosclerosis (70). Additionally, atherosclerotic lesions of human intima are known to have an increased collagen content (71) and collagen type I was reported to be the prominent form in the diseased vessels (72).

The results of the studies reported here suggest that the migration of SMC and monocytes into the subendothelial space of the early atherosclerotic lesion may lead to cell-cell interactions that result in production of several biologically important molecules that may amplify lesion development. Consistent with this notion are our recent findings that high levels of M-CSF mRNA are present in the atherosclerotic lesions of both Watanabe heritable hyperlipidemic and cholesterol-fed rabbits (73).

\section{Acknowledgments}

We thank Drs. Denise C. Polacek, Peter Davies, and David L. Paul for providing us with cDNA probes for connexins; Drs. Matt Ashby, Judith Berliner, Peter Edwards, and Catherine Clarke, for valuable discussions; Dr. David Woo for providing us with TGF- $\beta$ cDNA probe; Dr. Phillip Koeffler for assistance with obtaining human bone marrow cells; Farah Elahi and Sima Afrasiabi for their excellent technical assistance; and the members of the UCLA Heart Transplant Team for collecting the aortic specimens. 
This work was supported in part by the U. S. Public Health Service grants HL-30568, IT 32 HL-07412, and RR 865 and by the Laubisch, Rachel Israel Berro, and M. K. Grey Funds.

\section{References}

1. Rhodin, J. A. G. 1980. Architecture of the vessel wall. In The Cardiovascular System II. D. F. Bohr, A. P. Somlyo, and H. V. Sparks, Jr., editors. Handb. Physiol. 1-31.

2. Ross, R. 1986. The pathogenesis of atherosclerosis: an update. $N$. Engl. J. Med. 314:488-500.

3. Davies, P. F., G. A. Truskey, H. B. Warren, S. E. O’Connor, and B. H Eisenhaure. 1985. Metabolic cooperation between vascular endothelial cells and smooth muscle cells in co-culture: changes in low density lipoprotein metabolism. J. Cell Biol. 101:871-879, 1985.

4. Hajjar, D. P., A. J. Marcus, and K. A. Hajjar. 1987. Interactions of arterial cells: studies on the mechanisms of endothelial cell modulation of cholesterol metabolism in co-cultured smooth muscle cells. J. Biol. Chem. 262:6976-6981.

5. Hajjar, D. P., D. J. Falcone, J. B. Amberson, and J. M. Heffon. 1985. Interaction of arterial cells. I. Endothelial cells alter cholesterol metabolism in co-cultured smooth muscle cells. J. Lipid Res. 26:1212-1223.

6. Merrilees, M. J., and L. Scott. 1981. Interaction of aortic endothelial and smooth muscle cells in culture: effect on glycosaminoglycan levels. Atherosclero sis. 39:147-161.

7. Antonelli-Orlidge, A., K. B. Sunders, S. R. Smith, and P. A. D'Amore. 1989. An activated form of transforming growth factor beta is produced by cocultures of endothelial cells and pericytes. Proc. Natl. Acad. Sci. USA. 86:45444548 .

8. Sato, Y., and D. B. Rifkin. 1989. Inhibition of endothelial cell movement by pericytes and smooth muscle cells: activation of a latent transforming growth factor beta 1-like molecule by plasmin during coculture. J. Cell Biol. 109:309315.

9. Larson, M., C. C. Haudenschild, and E. C. Beyer. 1990. Gap junction messenger RNA expression by vascular wall cells. Circ. Res. 66:1074-1080.

10. Lash, J. A., E. S. Critser, and M. L. Pressler. 1990. Cloning of a gap junctional protein from vascular smooth muscle and expression in two cell mouse embryos. J. Biol. Chem. 265:13113-13117.

11. Corsaro, C. M., and B. R. Migeon. 1977. Contact mediated communication of oubain resistance in mammalian cells in culture. Nature (Lond.). 268:737-739.

12. Barr, L., M. M. Dewey, and W. Berger. 1965. Propagation of action potential and the structure of the nexus in cardiac muscle. J. Gen. Physiol. 48:797-823.

13. Loewenstein, W. R. 1966. Permeability of membrane junctions. Ann. N.Y. Acad. Sci. 137:441-472.

14. Subak-Share, H., R. R. Burk, and J. D. Pitts. 1969. Metabolic cooperation between biochemically marked mammalian cells in tissue culture. J. Cell Science. 4:353-367.

15. Navab, M., G. P. Hough, J. A. Berliner, J. A. Frank, A. M. Fogelman, M. E. Haberland, and P. A. Edwards. 1986. Rabbit beta-migrating very low density lipoprotein increases endothelial macromolecular transport without altering electrical resistance. J. Clin. Invest. 78:389-397.

16. Navab, M., G. P. Hough, B. J. Van Lenten, J. A. Berliner, and A. M Fogelman. 1988. Low density lipoproteins transfer bacterial lipopolysaccharides across endothelial monolayers in a biologically active form. J. Clin. Invest 81:601-605.

17. Paul, D. L. 1986. Molecular cloning of cDNA for rat liver gap junction protein. J. Cell Biol. 103:123-134.

18. Beyer, E. C., Paul, D. L., and D. A. Goodenough. 1987. Connexin43: a protein from rat heart homologous to a gap junction protein from liver. J. Cell Biol. 105:2621-2629.

19. Navab, M., G. P. Hough, L. W. Stevenson, D. C. Drinkwater, H. Laks, and A. M. Fogelman. 1988. Monocyte migration into the subendothelial space of a coculture of adult human aortic endothelial and smooth muscle cells. $J$. Clin. Invest. 82:1853-1863.

20. Fogelman, A. M., F. Elahi, K. Sykes, B. J. Van Lenten, M. C. Territo, and J. A. Berliner. 1988. Modification of the Recalde method for the isolation of human monocytes. J. Lipid Res. 29:1243-1247.

21. Freshney, R. I. 1987. Culture of Animal Cells. Alan R. Liss, Inc., New York. 216-225, 229-232.

22. Wakefield, L. M., D. M. Smith, T. Massui, C. C. Harris, and M. B. Sporn. 1987. Distribution and modulation of the cellular receptor for transforming growth factor-beta. J. Cell Biol. 105:965-97.

23. Chomczynski, P., and S. Nicoletta. Single step method of RNA isolation by acid guanidinium thiocyanate-phenol-chloroform extraction. 1987. Anal. Bio chem. 162:156-159.

24. Rajavashisth, T. B., R. Eng, R. K. Shadduck, A. Waheed, C. M. BenAvram, J. E. Shively, and A. J. Lusis. 1987. Cloning and tissue-specific expression of mouse macrophage colony stimulating factor mRNA. Proc. Natl. Acad. Sci. USA. 84:1157-1161.

25. Feinberg, A. P., and B. Vogelstein. 1983. A technique for radiolabeling DNA restriction endonuclease fragments to high specific activity. Anal. Biochem. 132:6-13.

26. Golde, D. W., and M. Cline. 1972. Identification of the colony-stimulating cell in human peripheral blood. J. Clin. Invest. 51:2981-2983.

27. Metcalf, D., C. G. Begley, G. R. Johnson, N. A. Nicola, M. A. Vadas, A. F Lopez, D. J. Williamson, G. G. Wong, S. C. Clark, and E. A. Wang. 1986. Biologic properties in vitro of recombinant human granulocyte-macrophage colony stimulating factor. Blood. 67:37-45.

28. Tucker, R. F., G. D. Shiply, H. L. Moses, and R. W. Holley. 1984. Growth inhibitor from BSC-1 cells closely related to platelet type beta transforming growth factor. Science (Wash. DC). 226:705-707.

29. Rosa, F., A. Roberts, D. Danielpour, L. L. Dart, M. B. Sporn, and I. B. Dawid. 1988. Mesoderm induction in amphibians: the role of TGF-beta 2-like factors. Science (Wash. DC). 239:783-785.

30. Edwards, P. A., S.-F. Lan, R. D. Tanaka, and A. M. Fogelman. 1983. Mevalonolactone inhibits the rate of synthesis and enhances the rate of degradation of 3-hydroxy-3-methylglutaryl coenzyme A reductase in rat hepatocytes. $J$. Biol. Chem. 258:7272-7275.

31. Dickinson, E. S., P. A. Dennis, and L. L. Slakey. 1986. Time course of release into the medium of newly synthesized proteins by cultured aortic endothelial cells. Arteriosclerosis. 6:627-637.

32. Laemmli, U. K. Cleavage of structural proteins during the assembly of the head of bacteriophage T. 1970. Nature (Lond.). 227:680-685.

33. Rasmussen, L. M., and L. Heickendorff. 1989. Quantification of fibronectin in extracts of human aorta by an ELISA. Scand. J. Clin. Lab. Invest. 49:205210 .

34. Schagger, H., and G. Von Jagow. 1987. Tricine-sodium dodecyl polyacrilamide gel electrophoresis for the separation of proteins. Anal. Biochem. 166:368-379.

35. Lowry, O. H., M. J. Rosebrough, A. L. Farr, and R. J. Randall. 1951. Protein measurement with the Folin phenol reagent. J. Biol. Chem. 193:265-275.

36. Stary, H. 1989. Evolution and progression of atherosclerotic lesions in coronary arteries of children and young adults. Arteriosclerosis. 9 (Suppl.):I 1932.

37. Jones, P. 1979. Construction of an artificial blood vessel wall from cultured endothelial and smooth muscle cells. Proc. Natl. Acad. Sci. USA. 76:18821886.

38. Davies, P. F., S. P. Olesen, D. E. Clapham, C. M. Morrel, and D. J. Shoen 1988. Endothelial communication: state of the art lecture. Hypertension. 11:583582.

39. Thoma, R. 1921. Über die Intima der Arterien. Virchows Arch. Pathol. Anat. Physiol. 230:1-45.

40. Bruns, R. R., and G. E. Palade. 1968. Studies on blood capillaries. I General organization of blood capillaries in muscle. J. Cell Biol. 37:244-276.

41. Huttner, I., M. Boutet, and R. H. More. 1973. Gap junctions in arterial endothelium. J. Cell Biol. 57:247-252.

42. Spagnoli, L. G., S. Villaschi, L. Neri, and G. Palmieri. 1982. Gap junctions in myo-endothelial bridges of rabbit carotid arteries. Experientia (Basel). 38:124-125.

43. Metcalf, D. 1989. The molecular control of cell division, differentiation commitment and maturation in haemopoietic cells. Nature (Lond.). 339:27-30.

44. Lang, R. A., D. Metcalf, R. A. Cuthbertson, I. Lyons, Stanley, E., A Kelso, Kannourakis, C., D. J. Williamson, C. K. Klinthworth, and T. J. Konda. 1987. Transgenic mice expressing a hematopoietic growth factor gene (GM-CSF) develop accumulation of macrophages, blindness, and a fatal syndrome of tissue damage. Cell. 51:875-86.

45. Sporn, M. B., and A. B. Roberts. 1985. Autocrine growth factors and cancer. Nature (Lond.). 313:745-747.

46. Roberts, A. B., M. B. Sporn, R. K. Assoian, J. M. Smith, N. S. Roche, L. M. Wakefield, U. I. Heine, L. A. Liotta, V. Falanga, J. H. Kehrl, et al. 1986. Transforming growth factor type-beta: rapid induction of fibrosis and angiogenesis in vivo and stimulation of collagen formation in vitro. Proc. Natl. Acad. Sci. USA. 83:4167-4171.

47. Roberts, C. J., T. M. Birkermeier, J. J. McQuillan, S. K. Akiyama, S. S. Yamada, W. T. Chen, K. M. Yamada, and J. A. McDonald. 1988. Transforming growth factor- $\beta$ stimulates the expression of fibronectin and of both subunits of the human fibronectin receptor by cultured human fibroblasts. J. Biol. Chem. 263:4586-4592.

48. Sato, Y., R. Tsuboi, R. Lyons, H. Moses, and D. B. Rifkin. 1990. Characterization of the activation of latent TGF- $\beta$ by cocultures of endothelial cells and pericytes or smooth muscle cells: a self-regulating system. J. Cell Biol. 111:757763.

49. Ignotz, R. A., and J. Massague. 1985. Transforming growth factor typebeta stimulates the expression of fibronectin and collagen and their incorporation into the extracellular matrix. $J$. Biol. Chem. 261:4337-4345.

50. Penttinen, R. P., Kobayashi, S., and Bornstein, P. Transforming growth 
factor $\beta$ increases mRNA for matrix proteins both in the presence and absence of changes in mRNA stability. Proc. Natl. Acad. Sci. USA. 85:1105-1108.

51. Liau, G., and L. M. Chan. 1989. Regulation of extracellular matrix RNA levels in cultured smooth muscle cells. J. Biol. Chem. 264:10315-10320.

52. McCaffery, T. A., D. J. Falcone, C. F. Brayton, L. A. Agarwal, F. G. P. Welt, and B. B. Weksler. 1989. Transforming growth factor- $\beta$ activity is potentiated by heparin via dissociation of the transforming growth factor- $\beta$ /alpha2-macroglobulin inactive complex. J. Cell Biol. 109:441-448.

53. Segarini, P. R., and S. M. Seyedin. 1988. The high molecular weight receptor to transforming growth factor- $\beta$ contains glycosaminoglycan chains. $J$. Biol. Chem. 263:8366-8370.

54. Madri, J. A., B. M. Pratt, and A. M. Tucker. 1988. Phenotypic modulation of endothelial cells by transforming growth factor- $\beta$ depends upon the composition and organization of the extracellular matrix. J. Cell Biol. 106:1375-1384.

55. Streuli, C. H., and M. J. Bissell. 1990. Expression of extracellular matrix components is regulated by substratum. J. Cell Biol. 110:1405-1415.

56. Lynch, S. E., R. B. Colvin, and H. N. Antoniades. 1989. Growth factors in wound healing. J. Clin. Invest. 84:640-646.

57. Majack, R. A., M. W. Majesky, and L. V. Goodman. 1990. Role of PDGF-A expression in the control of vascular smooth muscle cell growth by transforming growth factor- $\beta$. J. Cell Biol. 111:239-247.

58. Sporn, M. B., and A. B. Roberts. 1988. Peptide growth factors are multifunctional. Nature (Lond.). 332:217-219.

59. Eghbali, B., J. A. Kessler, and D. C. Spray. 1990. Expression of gap junction channels in communication-incompetent cells after stable transfection with cDNA encoding connexin 32. Proc. Natl. Acad. Sci. USA. 87:1328-1331.

60. Dayer, J. M., B. de Rochemonteix, B. Burrus, S. Demczuk, and C. A. Dinarello. 1986. Human recombinant interleukin 1 stimulates collagenase and prostaglandin E2 production by human synovial cells. J. Clin. Invest. 77:645648.

61. Adams, D. O., and T. A. Hamilton. 1984. The cell biology of macrophage activation. Annu. Rev. Immunol. 2:283-298.

62. Hagiwara, T., I. Kono, K. Nemoto, H. Kashiwagi, and K. Onozaki. 1989. Recombinant interleukin-1 triggers the increase of circulating fibronectin levels in rats. Int. Arch. Allergy Appl. Immunol. 89:376-380.
63. Montesano, R., A. Mossaz, J.-E. Ryser, L. Orci, and P. Vassalli. 1984. Leukocyte interleukins induce cultured endothelial cells to produce a highly organized glycosaminoglycan rich pericellular matrix. J. Cell Biol. 99:1706-1715.

64. Elias, J. A., and V. Lentz. 1990. IL-1 and tumor necrosis factor synergistically stimulate fibroblast IL-6 production and stabilize IL-6 messenger RNA. $J$. Immunol. 145:161-166.

65. Hagiwara, T., H. Suzuki, I. Kono, H. Kashiwagi, Y. Akiyama, and K. Onozaki. 1990. Regulation of fibronectin synthesis by interleukin-1 and interleukin-6 in rat hepatocytes. Am. J. Pathol. 136:39-47.

66. Lanser, M. E., and G. E. Brown. 1989. Stimulation of rat hepatocyte fibronectin production by monocyte condition medium is due to interleukin $6 . J$. Exp. Med. 170:1781-1786.

67. Mecham, R. P., L. A. Whitehouse, D. S. Wrenn, W. C. Parks, G. C. Griffin, R. M. Senior, E. C. Crouch, K. R. Sternmark, and N. F. Voelkel. 1987. Smooth-muscle mediated connective tissue remodeling in pulmonary hypertension. Science (Wash. DC). 237:423-426.

68. Uematsu, M., J. Tanouchi, K. Ishihara, K. Fujii, Y. Toshida, Y. Doi, and T. Kamada. 1989. Hypercholesterolemia without mechanical interventions induces early accumulation of fibronectin during fatty streak formation. Arteriosclerosis. 9:769a. (Abstr.)

69. Shekhonin, B. V., S. P. Domogatsky, G. L. Idelson, V. E. Koteliansky, and V. S. Rukosuev. 1987. Relative distribution of fibronectin and type I, III, IV, V collagens in normal and atherosclerotic intima of human arteries. Atherosclerosis. 67:9-16.

70. Mayne, R. 1986. Collagenous proteins of blood vessels. Arteriosclerosis. 6:585-593.

71. Levene, C. I., and J. C. F. Poole. 1962. The collagen content of the normal and atherosclerotic human aortic intima. Br. J. Exp. Pathol. 43:469-471.

72. Smith, E. B. 1965. The influence of age and atherosclerosis on the chemistry of aortic intima. J. Atheroscler. Res. 5:241-248.

73. Rajavashisth, T. B., A. Andalibi, M. C. Territo, J. A. Berliner, M. Navab, A. M. Fogelman, and A. J. Lusis. 1990. Modified low density lipoproteins induce endothelial cell expression of granulocyte and macrophage colony stimulating factors. Nature (Lond.). 344:254-257. 